\title{
Analysis of Effect of Bulbous Bow Shape to Ship Resistance in Catamaran Boat
}

\author{
Deddy Chrismianto ${ }^{1, *}$, Kiryanto $^{1}$, and Berlian Arswendo Adietya ${ }^{1}$ \\ ${ }^{1}$ Department of Naval Architecture, Faculty of Engineering, Diponegoro Univerity, Indonesia
}

\begin{abstract}
Ship resistance is one of the main factors affecting the design of a ship. Catamaran boat is a ship with small wet surface area that able to reduce drag and improve ship power. Generally, a bulbous bow is implemented to reduce wave resistance because the bulbous shape is believed to attenuate the bow wave system. Additionally, the bulbous bow also tends to reduce viscous resistance. When the flow around the body is smooth, the total ship resistance can be reduced significantly if the optimum bulbous bow is obtained. In this study, the main purpose is to get the bulbous bow shape in catamaran boat which produces the smallest ship resistance by using computational fluid dynamic (CFD). Generating the variation of the bulbous bow shapes apply the one-to-one correspondence of the cross section parameter $\left(\mathrm{A}_{\mathrm{BT}}\right)$ and lateral parameter $\left(\mathrm{A}_{\mathrm{BL}}\right)$. The result of investigation shows that application of bulbous bow on catamaran boat can reduce about $11-13 \%$ of total resistance of ship.
\end{abstract}

\section{Introduction}

A bulbous bow is a protruding bulb at the bow of a ship just below the waterline. The bulb modifies the way the water flows around the hull, reducing drag and thus increasing speed, range, fuel efficiency, and stability. Ships with bulbous bows generally have a 12 to 15 percent better fuel efficiency than similar vessels without them.

During the last decade catamaran boats have rapidly evolved into a dominant mode of sea transportation in Indonesian sea. Their particular area of proliferation is the short sea shipping where they show considerable superiority over competitive designs in attributes such as space availability and speed quality. However, resistance or drag characteristics are principal aspects of the catamaran boat design spiral as they are strongly coupled with speed and ship fuel and, consequently, the ship operating cost is one of problem on the catamaran boat that has to be solved.

Development of bulbous bow design for catamaran boat is a proposed model to solve the fuel problem. CAD-integrated CFD method is applied to obtain the better bulbous bow form of catamaran boat with minimum ship resistance. Recently, some of the studies CADintegrated CFD and optimization method can be used simultaneously to solve any problems, including the optimization of hull shape. The use of the control points of the cubic B spline to generate the parametric of ship hull design as well as the parametric of

* Corresponding author: deddy.chrismianto@ft.undip.ac.id 
bulbous bow design has been introduced with successful results [1, 2, 3, 4]. Deddy, C [5, 6] has developed the parametric bulbous bow design and submarine design are constructed using the cubic Bezier curve method and the curve-plane intersection method. The methods can be used to generate a parametric bulbous bow shape automatically using solid modeling for the optimization calculation in the effort to minimize the ship's resistance.

The non-linear bulbous bow parameter is investigated and varied to modify the bulbous bow form of catamaran boat by the cross section parameter $\left(\mathrm{A}_{\mathrm{BT}}\right)$ and lateral parameter $\left(\mathrm{A}_{\mathrm{BL}}\right)$. Generating the variation of the bulbous bow shapes apply the one-to-one correspondence of both parameters. The best of bulbous bow of catamaran boat is obtained with good performance that is able to save energy or fuel.

\section{Bulbous Bow Design}

Generally, a bulbous bow is implemented to reduce wave resistance because the bulbous shape is believed to attenuate the bow wave system. Additionally, the bulbous bow also tends to reduce viscous resistance. When the flow around the body is smooth, the total resistance can be reduced significantly if the optimum bulbous bow is obtained. There are some parameters that affect the dimension and form of the bulbous bow (Fig.1).

Kracht [7] classified the bulbous bow parameters into six quantitative parameters, including three linear parameters and three nonlinear parameters as follows:

- The breadth coefficient $C_{B B}$ : the maximum breadth $B_{B}$ of the bulbous bow sectional area at the FP is divided by the beam $\mathrm{B}_{\mathrm{MS}}$ of the ship, which is denoted by

$$
\mathrm{C}_{\mathrm{BB}}=\mathrm{B}_{\mathrm{B}} / \mathrm{B}_{\mathrm{MS}}
$$

The length coefficient $C_{L P R}$ : the bulbous bow length $L_{P R}$ is divided by the $L_{P P}$ of the ship; it is denoted by

$$
\mathrm{C}_{\mathrm{LPR}}=\mathrm{L}_{\mathrm{PR}} / \mathrm{L}_{\mathrm{WL}}
$$

- The depth coefficient $C_{Z B}$ : the height $Z_{B}$ of the bulbous bow tip is divided by the draft $\mathrm{T}_{\mathrm{FP}}$ at the FP; it is denoted by

$$
\mathrm{C}_{\mathrm{ZB}}=\mathrm{Z}_{\mathrm{B}} / \mathrm{T}_{\mathrm{FP}}
$$

- The cross section coefficient $\mathrm{C}_{\mathrm{ABT}}$ : the cross sectional area $\mathrm{A}_{\mathrm{BT}}$ of the bulbous bow at the FP is divided by the midship section area $\mathrm{A}_{\mathrm{MS}}$ of the ship, and it is denoted by

$$
\mathrm{C}_{\mathrm{ABT}}=\mathrm{A}_{\mathrm{BT}} / \mathrm{A}_{\mathrm{MS}}
$$

- The lateral coefficient $C_{\mathrm{ABL}}$ : the area of the bulbous bow in the longitudinal plane at center line $\mathrm{A}_{\mathrm{BL}}$ is divided by the midship section area $\mathrm{A}_{\mathrm{MS}}$ of the ship, and it is denoted by

$$
\mathrm{C}_{\mathrm{ABL}}=\mathrm{A}_{\mathrm{BL}} / \mathrm{A}_{\mathrm{MS}}
$$

- The volumetric coefficient $C_{\forall \mathrm{PR}}$ : the volume of the bulbous bow $\forall_{\mathrm{PR}}$ is divided by the volume of displacement $\forall_{\mathrm{WL}}$, and it is denoted by

$$
\mathrm{C}_{\forall \mathrm{PR}}=\forall_{\mathrm{PR}} / \forall_{\mathrm{WL}}
$$

Some previous research have analyzed the effect of linear parameters of bulbous bow. The nabla type of bulbous bow can reduce ship resistance significantly. This type has bigger value of dept coefficient $\mathrm{C}_{\mathrm{ZB}}$ than other types. So, in this study, the non-linear parameters of bulbous bow is chosen to be investigated its effect on the nabla type of bulbous bow. The cross section coefficient $\mathrm{C}_{\mathrm{ABT}}$ and lateral coefficient $\mathrm{C}_{\mathrm{ABL}}$ is applied to obtain the minimum ship resistance on the nabla type. $\mathrm{C}_{\mathrm{ABT}}$ has value around $0.064-0.122$ 
and $\mathrm{C}_{\mathrm{ABL}}$ is $0.068-0.146$. These values are combined in several bulbous bow models. (Table 1)

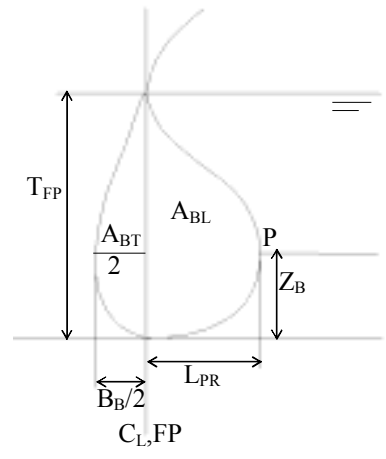

Fig. 1. Bulbous bow dimension

Table 1. Bulbous bow models based on $\mathrm{C}_{\mathrm{ABT}}$ and $\mathrm{C}_{\mathrm{ABL}}$ Values

\begin{tabular}{|c|c|c|c|c|}
\hline No & $\mathbf{C}_{\mathbf{A B T}}$ & $\mathbf{A}_{\mathbf{B T}}\left(\mathbf{m}^{\mathbf{2}}\right)$ & $\mathbf{C}_{\mathbf{A B L}}$ & $\mathbf{A}_{\mathbf{B L}}\left(\mathbf{m}^{\mathbf{2}}\right)$ \\
\hline Model 0 & - & 0.065 & - & 0.123 \\
\hline Model 1 & 0.064 & 0.126 & 0.068 & 0.134 \\
\hline Model 2 & 0.064 & 0.126 & 0.107 & 0.211 \\
\hline Model 3 & 0.064 & 0.126 & 0.146 & 0.288 \\
\hline Model 4 & 0.093 & 0.183 & 0.068 & 0.134 \\
\hline Model 5 & 0.093 & 0.183 & 0.107 & 0.211 \\
\hline Model 6 & 0.093 & 0.183 & 0.146 & 0.288 \\
\hline Model 7 & 0.122 & 0.240 & 0.068 & 0.134 \\
\hline Model 8 & 0.122 & 0.240 & 0.107 & 0.211 \\
\hline Model 9 & 0.122 & 0.240 & 0.146 & 0.288 \\
\hline
\end{tabular}

\section{Resistance calculation and results}

Catamaran boat without a bulbous bow owned by PT. Sanur Marindo Shipyard is modified and fitted a bulbous bow. This boat has main dimension, such as length perpendicular (Lpp) about $23.45 \mathrm{~m}$, breadth $9.00 \mathrm{~m}$, and draft $1.00 \mathrm{~m}$. One to one correspondency method is used to create several models with diiference of cross section coefficient $\mathrm{C}_{\mathrm{ABT}}$ and lateral coefficient $\mathrm{C}_{\mathrm{ABL}}$. There are 9 (nine) of models that be generated with the different linesplans of bulbous form (Fig.2).

Total resistance of ship is calculated using CFD with 3 (three) various of speed, that are: 16 knot, 20 knot, and 24 knot. Table 2 shows that applied bulbous bow on the catamaran boat is able to reduce drag significantly in all of speed. Model no. 8 is the best of bulbous bow form in which it has total resistance about $32.31 \mathrm{kN}$ in $16 \mathrm{knot}$ speed, 44.94 $\mathrm{kN}$ in 20 knot spped, and about $59.53 \mathrm{kN}$ in 24 knot speed. It shows that the total ship resistance value can be reduced up to $11-13 \%$.

In Fig. 3 described the wave pattern of catamaran boat between original model (model no. 0) and the best model (model no. 8). Comparison of both show several change of color in wave pattern, especially around the bow areas. The yellow color of wave pattern on model no. 8 has reduced compared with original model. This model is able to reduce the wave resistance significantly around bow areas. This fact explained that the wave resistance also shows reducing drag significantly about $21-22,5 \%$. 


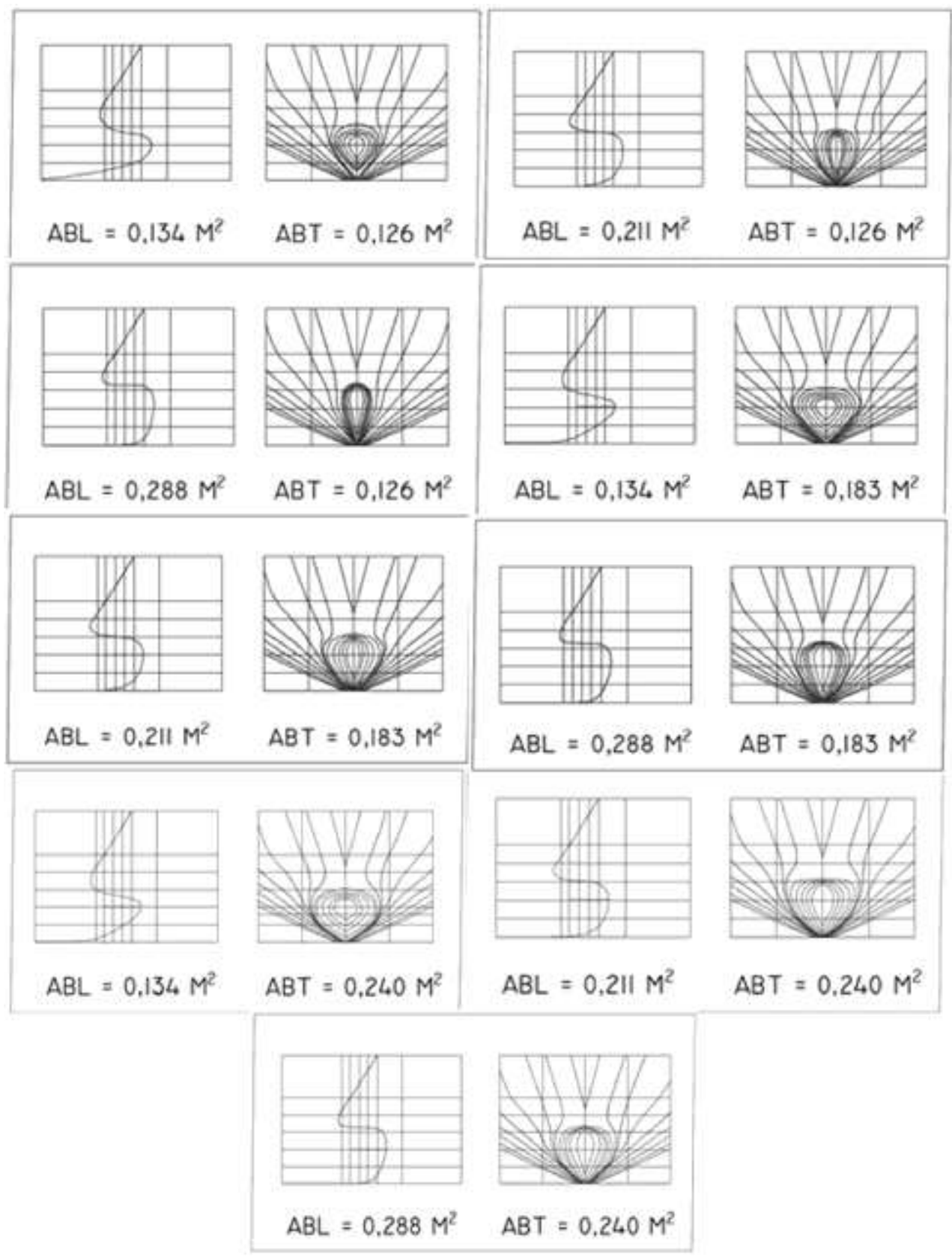

Fig. 2. Linesplan of bulbous bow models based on $A_{B T}$ and $A_{B L}$ 
Table 2. Calculation of total resistance in each model

\begin{tabular}{|c|c|c|c|}
\hline \multirow{2}{*}{ Model } & \multicolumn{3}{|c|}{ Total Resistance Value (kN) } \\
\cline { 2 - 4 } & $\mathbf{1 6}$ Knot & 20 Knot & 24 Knot \\
\hline Model 0 & 36.45 & 51.49 & 67.36 \\
\hline Model 1 & 35.17 & 50.27 & 64.83 \\
\hline Model 2 & 36.94 & 50.68 & 65.35 \\
\hline Model 3 & 35.90 & 50.22 & 63.50 \\
\hline Model 4 & 33.65 & 48.12 & 62.37 \\
\hline Model 5 & 34.29 & 48.06 & 62.67 \\
\hline Model 6 & 33.79 & 46.90 & 60.75 \\
\hline Model 7 & 33.98 & 46.89 & 60.60 \\
\hline Model 8 & 32.31 & 44.94 & 59.53 \\
\hline Model 9 & 35.72 & 49.67 & 64.42 \\
\hline
\end{tabular}

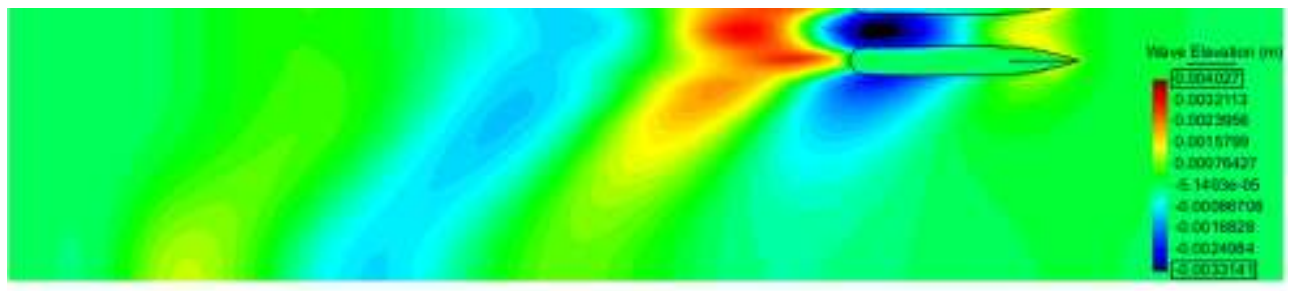

(a)

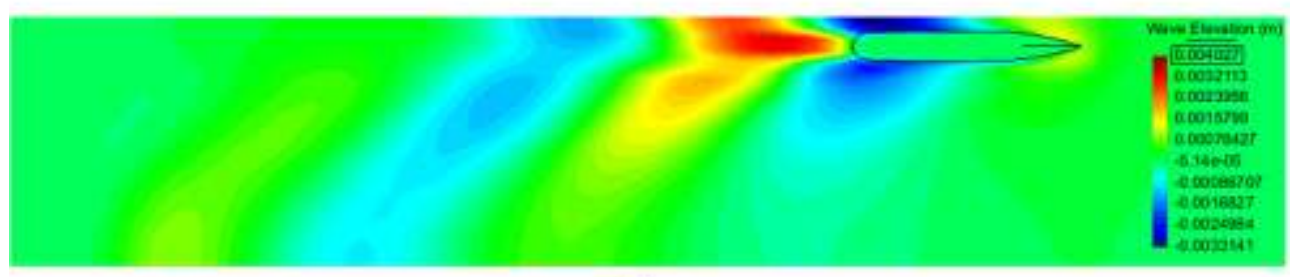

(b)

Fig. 3. Comparison of wave resistance at original model (a) and model no. 8 (b)

I would to thank to Faculty of Engineering Diponegoro University, Research Grant of DIPA FT - UNDIP, Penelitian Strategis Tahun 2017.

\section{Conclusion}

1. Based on the CFD analysis result, it was found that ship resistance value for various variations of bulbous bow shape in catamaran boat. Model no. 8 has the smallest value of ship total resistance.

2. The total ship resistance value can be reduced up to $11-13 \%$ on model no. 8 of catamaran boat, this value occurs at a speed of $16-24$ knots. The bulbous bow shape has $\mathrm{A}_{\mathrm{BT}}=0.211 \mathrm{~m} 2$ and $\mathrm{A}_{\mathrm{BL}}=0.240 \mathrm{~m} 2$. 
3. Model no. 8 (best model) has fewer yellow color at the bow area than model no. 0 (original model). This fact explained that the wave resistance also shows reducing drag significantly about $21-22,5 \%$.

\section{References}

1. F. Perez, J.A. Suarez, J.A. Clemente, A.Souto, J Mar Sci Technol 12, 83-94 (2007)

2. Z. Ping, Z.D. Xiang, L.W. Hao, J. Hydrodynamics 20, 804-810 (2008)

3. F. Perez, J.A. Clemente, Computer-Aided Design 43, 1829-1840 (2011)

4. E.F. Campana, D. Peri, Y. Tahara, F. Stern, Comput. Methods Appl. Mech. Engrg, 196, 634-651 (2006)

5. D. Chrismianto, D.J. Kim, J. Mar. Sci. Technol. 19, 479-492 (2014)

6. D. Chrismianto, A. F. Zakki, B. Arswendo, D.J. Kim, J. Marine Sci. Appl. 14, 399405 (2015)

7. Kracht, M. Alfred, SNAME Transactions 86, 197-217 (1978)

8. Lewis, V Edward, Principles of Naval Architecture Vol. II: Resistance and Propulsion (SNAME, New Jersey, 1988) 